\title{
CLASSES MULTISSERIADAS: PRÁTICAS, MEMÓRIAS E FORMAÇÃO DOCENTE
}

\author{
Mara Rita Duarte de OLIVEIRA ${ }^{1}$ \\ Universidade Federal do Pará/UFPA \\ mrdoma@ufpa.br \\ Nazareno do Socorro da Silva OLIVEIRA ${ }^{2}$ \\ Semec/Igarapé-Miri - UFPA/ \\ nazaoliveira@bol.com.br
}

Resumo: A presente pesquisa teve como objetivo principal analisar as práticas pedagógicas de docentes em classes multisseriadas, das escolas do campo, localizadas no Município de Igarapé-Miri. Realizamos a sistematização das experiências vividas pelos professores em sala de aula relacionando o que os professores sabem, como produzem seus saberes docentes, culturais e pedagógicos, como transmitem esses saberes produzidos no interior de suas práticas. Utilizamos informações concedidas por esses sujeitos através de entrevistas na forma de narrativas memorialísticas, acompanhamos o cotidiano escolar das escolas, assim como visitamos as comunidades rurais onde essas escolas estão inseridas.

1 Doutora em Educação. Professora do curso de Pedagogia da Universidade Federal do Pará - Campus Universitário de Abaetetuba. Coordenadora do Grupo de Estudos e Pesquisa Memória, Formação Docente e Tecnologia (GEPEMe/UFPA).

2 Aluno do Curso de Licenciatura em Educação do Campo do Campus Universitário de Abaetetuba Pará. Professor da Rede Básica de Ensino do Município de Igarapé-Miri. Membro do Grupo de Estudos e Pesquisa Memória, Formação Docente e Tecnologia (GEPEMe/UFPA). 
Palavras-chaves: Saberes docentes. Práticas docentes. Classes multisseriadas.

\begin{abstract}
This research aimed to examine the pedagogical practices of teachers in multigrade classes, school field, located in the Municipality of Igarapé-Miri. We conducted the systematization of experiences by teachers in the classroom relating what teachers know, how they produce their teachers, cultural and pedagogical knowledge, as these transmit knowledge produced within their practices. We use information provided by these subjects through interviews as memorialistic narratives, we follow the school routine of schools, as well as visit the rural communities in which these schools are located.
\end{abstract}

Keyswords: Knowledge teachers. Teaching practices. Multigrade classes.

\title{
1. Introdução
}

Sabemos que multissérie é uma modalidade de ensino presente na realidade do campo brasileiro. Para compreendermos melhor como estão organizadas essas classes, é importante analisar como se define essa forma de organização do ensino e do trabalho pedagógico e a forma como se dá o agrupamento dos alunos em diferentes níveis de aprendizagem e idades. Essa organização dos espaços e tempos pedagógicos tem como objetivo, principalmente, atender a necessidades educativas dos alunos e também os arranjos formais dos sistemas de ensino. São formadas, sobretudo, em locais onde há poucos alunos nas séries escolares que moram em localidades/comunidades rurais distantes de escolas-sedes, que agregam o maior número de alunos. Em uma mesma classe, são encontrados alunos com diferentes idades e diferentes etapas de escolaridade. Essa organização escolar traz maior dificuldade para o planejamento dos professores, o que tange ao processo de ensino-aprendizagem, pois exige a elaboração de estratégias variadas, para atender não apenas as diferentes necessidades de conteúdos, como também a grande variação de interesses e modos de interação resultante das diferenças de faixas etárias dos alunos. No entanto, é um modelo que possibilita que pequenas comunidades rurais, com poucas crianças, não tenham que se deslocar para regiões mais distantes.

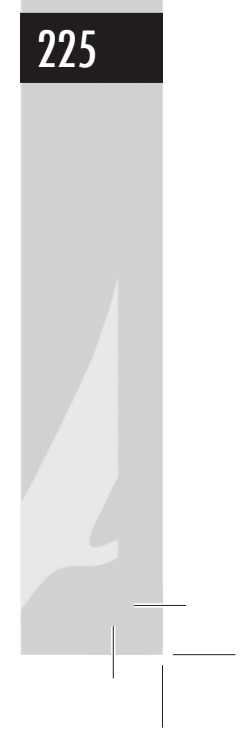




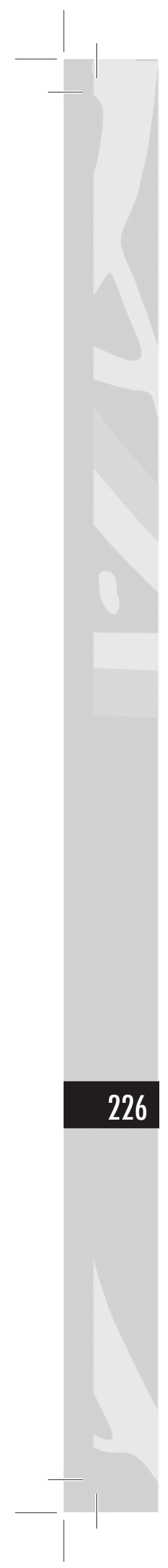

A permanência dos alunos em seu próprio espaço sociocultural possibilita uma maior articulação com a comunidade, e os saberes produzidos nessa organização social possibilitam a oportunidade de esses alunos atuarem na realidade, a partir da compreensão da mesma, associando os saberes culturais aos saberes históricos produzidos pela humanidade.

Para compreendermos melhor como se constitui essa modalidade de ensino é importante analisar e compreender o processo histórico pelo qual a educação do campo passou e construindo-se constrói até os dias de hoje, quando podemos identificar desde a mudança da expressão "rural" para a expressão "campo" pelo fato de essa última expressão abordar com maior intensidade o público envolvido nesse espaço.

Observamos que no Brasil o mundo agrário se desenvolveu a partir da lógica do colonialismo, o latifundiário e o trabalho escravo. A educação do campo não é contemplada nesse contexto, pois a educação é voltada para os setores da sociedade que vão compor e ocupar os espaços e processos de industrialização. Quando a educação aparece nesse cenário, é usada como instrumento de controle para o crescente movimento migratório da população dos espaços rurais para os urbanos com a promessa de elevar a produtividade no campo.

Nesse contexto, de profundas contradições, houve um grande desenvolvimento da produção agrícola nesse período, patrocinado e gerido por organismos de cooperação norteamericana e difundido através de sistema de assistência técnica e extensão rural. No entanto, esse desenvolvimento não atende as necessidades educacionais das pessoas que vivem nesse lugar, pois esse modelo, segundo Leite (1999), tinha

conteúdos focados no processo de urbanização e industrialização; privilegiava interesses de certas classes sociais e não considerava a diversidade dos sujeitos sociais existentes no Brasil rural e urbano, a sua cultura, as suas diversas formas de organizar o trabalho $e$ a vida e privilegiava conhecimentos relativos ao mundo ocidental industrializado (p.30-31). 
Partindo dessas observações, é possivel compreender por que o meio rural no Brasil apresenta um dos mais baixos índices de escolaridade do mundo. Nessa realidade, tentamos compreender os processos educativos e as práticas docentes das classes multisseriadas na Amazônia.

Nesse sentido, colocamos como objetivo central do presente estudo: analisar as práticas dos professores que atuam em classes multisseriadas, a partir dos registros das narrativas memorialísticas desses professores acerca de suas próprias práticas pedagógicas; compreender a escola a partir das análises realizadas no cotidiano escola e da escuta das narrativas memorialísticas dos professores que fizeram parte da referida pesquisa ${ }^{3}$.

\section{Metodologia}

$\mathrm{Na}$ última década, vários pesquisadores do campo da educação vêm adotando as narrativas de professores como metodologias da investigação da prática docente. O emprego das narrativas de professores como objeto de investigação é fruto da necessidade de trabalhar de forma mais específica experiências mais especificas da docência, como uma forma de considerar as vivências dos professores no desenvolvimento de suas atividades educacionais.

Portanto, utilizamos a história oral como metodologia de pesquisa, pois, desse modo, entendemos que a pesquisa narrativa procura sistematizar as experiências vividas pelos professores no contexto educacional. Através das informações concedidas por esses sujeitos, foi possível relacionar os conhecimentos sobre o que os professores sabem como produzem seus saberes, como transmitem o saber produzido. Essas buscas identificam os conhecimentos utilizados no desenvolvimento de suas práticas pedagógicas e a forma como constroem seus conhecimentos e realizam suas práticas docentes.

3 Pesquisa financiada pelo PIBIC/ Interior da Universidade Federal do Pará. 


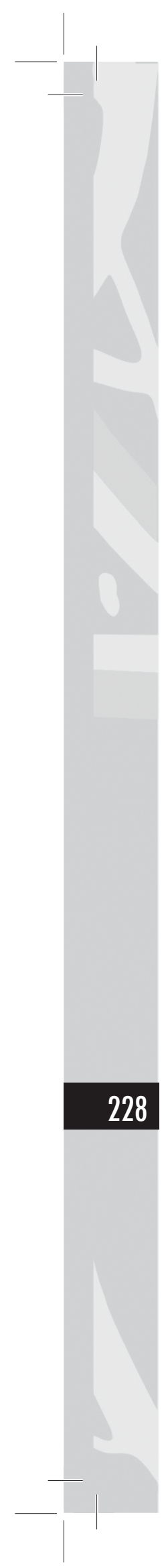

Também realizamos a observação, in loco, como estratégia de aproximação da realidade investigada. Através da observação participante compreendemos a relação professor e aluno, como eram desenvolvidas metodologias de ensino pelos professores no processo de ensino e aprendizagem no cotidiano escolar. No processo de coleta de dados in loco, entrevistamos 15 professores, aplicamos um modelo de questionários com questões relacionadas à docência, infraestrutura, condições do trabalho docente, gestão e financiamento. Também visitamos 20 famílias para conhecermos a comunidade local e realizamos uma reunião com os pais para falarmos do objetivo da pesquisa e sabermos o que pensavam da escola. Após os dados coletados, realizamos o processo de análise das entrevistas, para apresentar a seguir os resultados alcançados.

\section{Formação e docência nas classes multisseriadas}

Para Arroyo (2000), a identidade profissional dos docentes é algo dinâmico, na qual devemos levar em consideração vários fatores, entre eles a própria construção elaborada pela sociedade. Ele ainda vai além, ressaltando que se deve lembrar que essa imagem social é resultado de uma variável dos diferentes contextos históricos, políticos, sociais e econômicos. Mas de qualquer forma, é diante das experiências cotidianas que vai se desenhando a própria identidade.

Para uma melhor visualização e entendimento dos saberes dos professores, Tardif (2011, p. 63) propõe um quadro com os saberes mobilizados pela prática pedagógica, destacando suas fontes sociais de aquisição e os modos de integração no trabalho docente, em uma tentativa de dar conta do pluralismo do saber profissional: 


\begin{tabular}{|l|l|l|}
\hline $\begin{array}{l}\text { Saberes dos } \\
\text { professores }\end{array}$ & Fontes sociais de aquisição & $\begin{array}{l}\text { Modos de } \\
\text { integração no } \\
\text { trabalho docente }\end{array}$ \\
\hline $\begin{array}{l}\text { Saberes pessoais dos } \\
\text { professores. }\end{array}$ & $\begin{array}{l}\text { A família, o ambiente de } \\
\text { vida, a educação no sentido } \\
\text { lato, etc. }\end{array}$ & $\begin{array}{l}\text { Pela história } \\
\text { de vida e pela } \\
\text { socialização } \\
\text { primária }\end{array}$ \\
\hline $\begin{array}{l}\text { Saberes provenientes } \\
\text { da formação escolar } \\
\text { anterior. }\end{array}$ & $\begin{array}{l}\text { A escola primária e } \\
\text { secundária, os estudos } \\
\text { pós-secundários não } \\
\text { especializados, etc. }\end{array}$ & $\begin{array}{l}\text { Pela formação e } \\
\text { pela Socialização } \\
\text { pré-profissionais. }\end{array}$ \\
\hline $\begin{array}{l}\text { Saberes provenientes } \\
\text { da formação } \\
\text { profissional para o } \\
\text { magistério. }\end{array}$ & $\begin{array}{l}\text { Os estabelecimentos de } \\
\text { formação de professores, } \\
\text { os estágios, cursos de } \\
\text { reciclagem, etc. }\end{array}$ & $\begin{array}{l}\text { pela formação e } \\
\text { profissionais } \\
\text { nas instituições } \\
\text { de formação de } \\
\text { professores. }\end{array}$ \\
\hline $\begin{array}{l}\text { Saberes provenientes } \\
\text { dos programas e } \\
\text { livros didáticos } \\
\text { usados no trabalho. }\end{array}$ & $\begin{array}{l}\text { "ferramentas" dos } \\
\text { professores: programas, } \\
\text { livros didáticos, cadernos de } \\
\text { exercícios, fichas, etc. }\end{array}$ & $\begin{array}{l}\text { Pela utilização } \\
\text { das “ferramentas" } \\
\text { adaptação às } \\
\text { tarefas. }\end{array}$ \\
\hline $\begin{array}{l}\text { Saberes provenientes } \\
\text { de sua própria } \\
\text { profieriência na na sala de } \\
\text { aula e na escola. }\end{array}$ & $\begin{array}{l}\text { A prática do ofício na } \\
\text { escola e na sala de aula, a } \\
\text { experiência dos pares, etc. }\end{array}$ & $\begin{array}{l}\text { Pela prática do } \\
\text { trabalho e pela } \\
\text { socialização } \\
\text { profissional. }\end{array}$ \\
\hline
\end{tabular}

Segundo o autor, todos os saberes identificados no quadro acima, são realmente utilizados pelos professores no contexto de sua profissão. Analisando o quadro supracitado percebermos as várias fontes das quais esses saberes são provenientes, espaços, tempos e finalidades diferenciadas que influenciam diretamente a prática docente dos professores. Ou seja, o saber profissional está na junção entre várias fontes de saberes provenientes da história de vida individual, da sociedade, da instituição escolar, da relação com outros atores educativos, dos lugares de formação, 
dentre outras, e seu desenvolvimento está associado tanto às suas fontes e lugares de aquisição quanto aos seus momentos e fases de construção.

Assim, a educação escolar, especialmente aquela que se processa na realidade do campo, deve ser entendida como meio de apropriação e possibilidade de criação de conhecimentos para os indivíduos através do domínio da leitura e da escrita inclusive, gerando um sujeito cognoscente capaz de se inserir criticamente no universo social da própria leitura e da escrita. Agindo numa perspectiva transformadora, exige um educador que articule saberes da experiência, com saberes da tradição e saberes científicos.

Ao compreendemos que os alunos das escolas do campo como quaisquer outros alunos têm o direito de acesso a políticas públicas de qualidade, entre elas uma educação que esteja relacionada à realidade local que leve em consideração as especificidades locais,

Pois de acordo com resolução (1/2002 - CNE/CEB) a.a identidade da escola do campo é definida pela sua vinculação às questões inerentes a sua realidade, ancorando-se na temporalidade e saberes próprios dos estudantes, na memória coletiva que sinaliza futuros, na rede de ciência e tecnologia disponível na sociedade e nos movimentos sociais em defesa de projetos que associem as soluções exigidas por essas questões à qualidade de vida coletiva no país.

Portanto, a multissérie é uma modalidade de ensino específico dessas regiões e pode contribuir para desenvolvimento do processo educacional desses povos, porém essa prática deve respeitar a realidade desse público escolar,

O senso escolar de 2006 revelou que, entre as 9.483 escolas rurais de educação básica existentes no estado do Pará, 891 estão localizadas em assento rural, 376 em colônias agrícolas, 8 em comunidades garimpeiras, 
109 em comunidade indígena, $12 \mathrm{em}$ comunidade praiana, $214 \mathrm{em}$ comunidade quilombola, $2.525 \mathrm{em}$ comunidades ribeirinhas, 3.550 em comunidade rural, $120 \mathrm{em}$ comunidade rural em fazenda e $1.678 \mathrm{em}$ comunidade vicinal.

Toda essa dimensão geográfica e diversidade social econômica e cultural nos permite compreender que a realidade das escolas do campo ainda se processa em um contexto de precariedade e dificuldades, em que o professor tem limitações para desenvolver as atividades didático-pedagógicas com qualidade, como aponta Hage (2011, p. 99)

As escolas multisseriadas estão localizadas em pequenas comunidades rurais, muito afastadas das sedes do município, nas quais a população a ser atendida não atinge um contingente definido pelas secretarias de educação para formar uma turma por série/ano. São escolas que apresentam infraestrutura precária: em muitas situações não possuem prédio próprio e funcionam na casa de um morador local ou em salões de festas, barracões, igrejas, etc. - lugares muito pequenos, construídos de forma inadequada em termos de ventilação iluminação, cobertura e piso, que se encontram em péssimo estado de conservação, com goteiras remendos e improvisações de toda ordem, causando riscos aos seus estudantes e professores. Grande parte delas tem somente uma sala de aula, onde se realizam as atividades pedagógicas e todas as demais atividades envolvendo os sujeitos da escola e da comunidade, e carece de outros espaços, como refeitórios, banheiros, local para armazenar a merenda ou outros materiais necessários. Além disso, o número de carteiras que essas escolas possuem nem sempre é suficiente para atender a demanda, $e$ os quadros de giz estão deteriorados dificultando a visibilidade dos alunos.

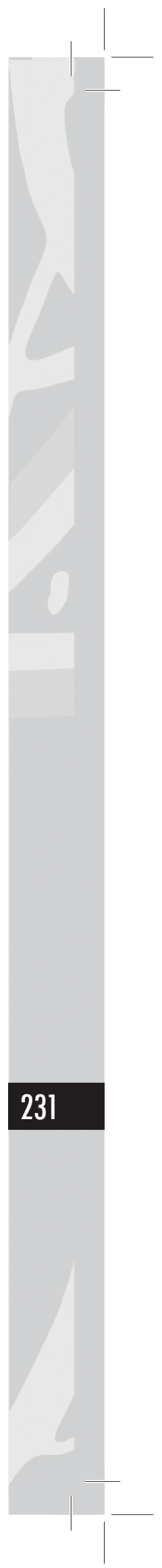


As dificuldades existentes nas escolas que se encontram nessas situações podem contribuir para que os alunos desenvolvam o processo educacional apesar de tantos problemas existentes nessas formas de organização do trabalho docente.

\section{As reflexões dos professores}

A presente pesquisa apontou algumas reflexões acerca da realidade da educação do campo e de suas necessidades individuais dos alunos das classes multisseriadas. Para compreender as práticas pedagógicas, contextualizadas, neste processo de pesquisa tentamos cada vez mais divulgar as práticas docentes que apresentam resultados exitosos, ao que se refere a produção do conhecimento e a forma como os professores conduzem o processo de ensino e aprendizagem; baseado na valorização da realidade local e na responsabilidade social e política dos professores com os alunos e a comunidade onde atuam.

Essas práticas contextualizadas foram sendo registradas nas narrativas dos professores entrevistados, entre elas destacamos a da professora Maria Izabel que iniciou sua rememoração docente afirmando que:

Comecei trabalhando com jovens e adultos e depois me identifiquei com a atividade, trabalhei seis anos de contrato, logo em seguida passei no concurso e estou atuando agora como efetiva epenso em melhorar minha prática para poder melhora o ensino e a aprendizagem dos alunos.

Ao falar de seu trabalho nas classes multisseriadas afirmou que:

Eu utilizo diversas metodologias para alcançar tais objetivos propostos na aula. Às vezes se eu trabalho língua portuguesa eu pego um assunto, um texto eu vou trabalhar esse texto do jardim I até o terceiro ano, aí eu só vou mudar as atividade, aí que vou diferenciar pra 
cada nível, exemplo pro jardim I eu vou usar as letras as vogais, consoantes, aí o terceiro ano já é uma atividade um pouco mais difícil com palavras, frases, substantivos, ou seja aquilo que eu não vou trabalhar mais nas series anteriores [...] eu acho que para o professor desenvolver bem sua pratica docente é ter uma boa formação com cursos de capacitação que é preciso a gente ter para poder acompanhar as inovações.

Trabalhar em uma turma multisseriada apresenta muitas dificuldades, mas podemos sim desenvolver o aspecto de educação dos alunos, pois trabalhar com alunos de diferentes idades e niveis de ensino podemos através de algumas metodologias como as crianças menores acabam aprendendo também com as maiores [...] e o que a gente espera como professor é formar cidadãos críticos para atuar na sociedade [...]

Entendemos que é necessário elevar o nível de alfabetização dos educandos inseridos nas classes multisseriadas, contribuindo com o fortalecimento das identidades coletivas e individuais, possibilitando apropriação dos diversos saberes dos povos do campo e permitindo a relação desses com os saberes científicos. É preciso que essa relação de alternância de saberes se construa de forma articulada com a realidade dos alunos. Pois, é importante que o processo de ensino e aprendizagem esteja relacionado com o contexto econômico, político e ambiental que esses alunos estão inseridos.

Porém, há de se destacar que, na realidade educacional brasileira, as políticas democráticas para os diversos setores da sociedade se constitui desafio à formação dos profissionais da educação do campo. A adoção de políticas econômicas neoliberais, a partir dos anos 1970, determinaram o agravamento dos problemas sociais que ainda enfrenta a maioria da população do campo brasileira. Tais problemas, em certa medida, determinaram o êxodo rural do campo, a baixa escolarização,

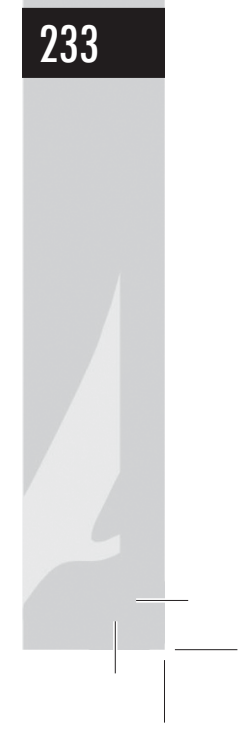




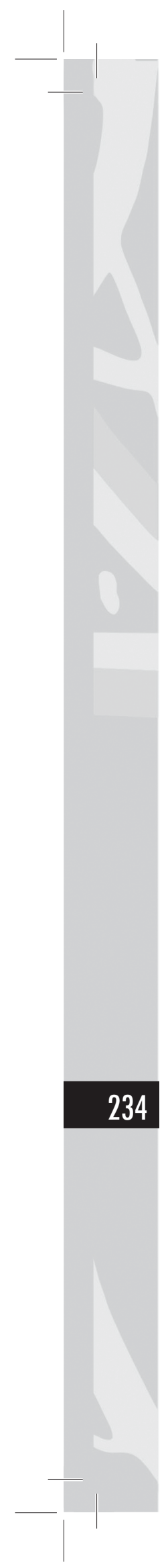

o analfabetismo e analfabetismo funcional, o desemprego e a violência na cidade e no campo.

Tal problemática demanda aos profissionais da educação a elaboração de projetos educativos de inclusão social, tanto na educação formal escolar, como em outros espaços com possibilidades de desenvolvimento de ações pedagógicas para ampliação cultural e social da população. Esse cenário imprime aos cursos de formação inicial e continuada dos profissionais da educação a responsabilidade social, para produzir conhecimento e realizar crítica, reflexiva e eficazmente um trabalho coletivo para a construção de um projeto educativo democratizador.

No que diz respeito à formação continuada, a LDBN/96 responsabiliza os sistemas de ensino em promover processos de formação continuada de seus profissionais. Conforme Gatti (2008, p. 58), as políticas para formação continuada buscam minimizar a problemática conjuntural da sociedade contemporânea, "nos desafios colocados aos currículos e ao ensino, nos desafios postos aos sistemas pelo acolhimento cada vez maior de crianças e jovens, nas dificuldades do dia a dia nos sistemas de ensino, anunciadas e enfrentadas por gestores e professores e constatadas e analisadas por pesquisas". Nesse sentido, a necessidade de oferecer aos professores, em processos de formação inicial e continuada, teorias críticas de educação que os orientem a realizar mediações no interior das escolas que produzam efeitos sociais emancipadores. Esta condição que tem a escola justifica a tese de que todo o ato educativo é político, uma vez que "produz este ou aquele efeito social, dependendo das forças sociais que nela atuam e com as quais ela se vincula" (SAVIANI, 1997, p. 60). Giroux (1997, p. 196) fornece contribuições para qualificar os processos de formação continuada, afirmando que é "preciso desenvolver programas nos quais os futuros professores possam ser educados como intelectuais transformadores e que sejam capazes de afirmar e praticar o discurso da liberdade e da democracia". Entende-se por intelectual transformador o professor capaz de participar de uma luta coletiva por emancipação. Num sentido mais amplo, o professor que compreenda os interesses políticos e ideológicos 
que estruturam a natureza do discurso, as relações sociais em sala de aula e os valores que eles legitimam em sua prática.

Para Giroux (1997, p. 161), encarar os professores como intelectuais fornece uma vigorosa crítica teórica das ideologias tecnocráticas e instrumentais subjacentes à teoria educacional que separa a conceitualização, planejamento e organização curricular dos processos de implementação e execução. O movimento de educadores brasileiros vem desde os anos 80 , denunciando a necessidade de políticas públicas voltadas à valorização docente e melhoria das condições de trabalho nas escolas públicas. Passados 30 anos, na atual conjuntura da aprovação do novo Plano Nacional da Educação (PNE), depara-se com a mesma luta, número reduzido de profissionais nas escolas, intensificação da jornada de trabalho para compensação dos baixos salários, precária estrutura física e segurança nas escolas.

\section{Considerações finais}

Essas experiências são marcadas pela compreensão de que é urgentemente preciso uma escola voltada para a realidade daqueles que habitam o campo, em igualdade social de oferta de escolarização e de qualidade de ensino. E é assim que se vão construindo tais iniciativas no contínuo devir dos processos históricos e sociais, sem se desconsiderar, é claro, a realidade desses grupos.

E é com base na crença de dar continuidade à transformação social e à cultura popular, que os movimentos sociais insistem em fazer, em construir, a história e celebrar seus compromissos com as lutas das populações do campo.

Acreditamos que não basta a otimização do acesso à escolarização básica, mas é necessário afiançar (e acima de tudo) os investimentos em projetos educacionais que se articulem melhor com as comunidades as quais devam beneficiar e não as marginalizando, em nenhum momento, dos processos decisórios.

Eis aí o porquê da importância das experiências da pedagogia da alternância e das escolas itinerantes do MST; constituem contribuições fundamentais para uma escola do 


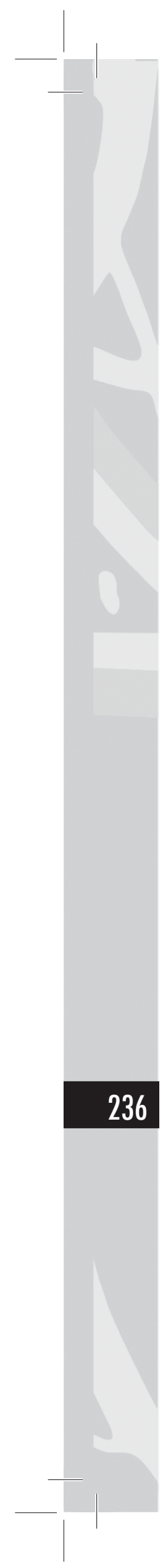

campo, emancipatória, reivindicativa e singular. Uma escola que seja um espaço político e pedagógico ao mesmo tempo, onde o tempo-escola e o tempo-comunidade se equacionem, onde professores e professoras assumam uma identidade cultural que lhes pertence e que os(as) educadores(as) desenvolvam práticas alternativas de ensino que desmonte a linguagem da lógica da dominação (GIROUX e MACLAREN, 1995, p. 140).

Uma ação docente-discente que abarque a dimensão cotidiana da escola, em que os sujeitos escolares atribuam sentido às suas vidas através das complexas formas históricas, culturais e políticas e não apenas as incorporem, mas que sejam capazes de produzi-las (GIROUX e MACLAREN, 1995, p. 145).

A escola deve ser um lugar gostoso (ASSMANN, 2000, p. 23) e ao mesmo tempo um espaço criativo para que os sujeitos escolares possam construir novos conhecimentos. $\mathrm{O}$ conhecimento só emerge em sua dimensão vitalizadora quando tem algum tipo de ligação com o prazer (ASSMANN, 2000, p. 30). Somente quando prazer e conhecimento estabelecem ligações é que a aprendizagem flui, e não como um amontoado de coisas que vão se reunindo, mas como um saber histórico com a marca do aprendiz.

Nesselongocaminho, cheiodeobstáculosedescontruções, é imprescindível uma revisão radical de valores, uma crítica ao modelo pedagógico que esteve e ainda está instituído em nossas escolas do campo.

E muito mais do que essa revisão radical de valores, é ainda necessário restabelecer parâmetros decisórios acerca dos projetos destinados às escolas, vislumbrando-se a elaboração de um projeto educacional coletivo, em parceria com todos os sujeitos envolvidos (alunos(as), professores(as), comunidade rurais e técnicos).

Estamos nos referindo a um projeto de educação do campo que não seja apenas um programa a ser implementado nas zonas rurais, mas que, fundamentalmente, desponta em suas próprias estruturas devido às necessidades e perspectivas das populações rurais (PETTY et al, 1981, p. 34). 
Fazer uma escola do campo possível, uma escola que leve em conta as peculiaridades e carências dos (as) aluno(as) e a elas se adapte nas metodologias, nos conteúdos e na organização do processo pedagógico (ARROYO, 1991, p. 27), e que, ao mesmo tempo, reconheça e valorize o significado social das manifestações culturais e atenda aos interesses coletivos daqueles que dela possam e querem se beneficiar é tarefa dos movimentos sociais atrelados à luta campesina.

\section{REFERÊNCIAS}

ARROYO, Miguel G.. Políticas de Formação de Educadores(as) do Campo. Cad. Cedes, Campinas, v. 27, n. 72, p. 157-176, maio/ago 2007. Disponível em: http://www.cedes.unicamp.br

. (Org.). Da escola carente à escola possível. São Paulo: Edições Loyola, 1991.

ASSMANN, Hugo. Reencantar a educação: Rumo à uma sociedade aprendente. $4^{\mathrm{a}}$ ed. Petrópolis: Vozes, 2000.

BRASIL. Secretaria de educação básica. Diretoria de apoio à gestão educacional. Pacto educacional pela educação na idade certa: planejamento do ensino na perspectiva da diversidade: educação do campo: unidade 02 / ministério da educação, Secretaria de educação básica diretoria de apoio à gestão educacional - Brasília: MEC, SEB, 2012.

DAMACENO, Handherson Costa. Leitura e as classes multissérie: o trabalho docente e a inserção dos alunos em práticas sociais de leitura. Revela, Bahia, ano III, no VI, out/2009, 2009. p. 01 a 16

GIROUX, Henry e MACLAREN, Peter. Formação do professor como uma contra-esfera pública: a pedagogia radical como uma 
forma de política cultural In: MOREIRA, Antonio Flávio e SILVA, Tomaz Tadeu da. (Orgs). Currículo, cultura e sociedade. $2^{\text {a }}$ ed. São Paulo: Cortez, 1995. p. 125 a 154

HAGE, Salomão. Por uma escola do campo de qualidade social: transgredindo o paradigma (multi)seriado de ensino. Em Aberto, Brasília, v. 24, no 85, abri, 2011.p. 97-113

A multissérie em pauta: para transgredir o paradigma seriado nas escolas do campo. In: I Encontro de Profissionais de Classes Multisseriadas das Escolas do Campo da Bahia. Salvador, 2009. http://www.faced.ufba.br/sites/faced.ufba.br/files/multisserie_ pauta_salomao_hage.pdf

LEITE, Sérgio Celani. Escola rural: Urbanização e políticas educacionais. São Paulo: Cortez, 1999.

PETTY, Miguel et al. Uma alternativa de educação rural. In: WERTEIN, Jorge e BORDENAVE, Juan Diaz. (Orgs.). Educação rural no terceiro mundo: Experiências e novas alternativas. Rio de janeiro: Paz e Terra, 1981.p. 31 a 63

SANTOS NETO, Elydio dos. (Auto)biográfica e formação de educadores: um olhar desde uma perspectiva transpessoal. Revista @mbienteeducação, São Paulo, v. 2, nº 2, agos/dez, 2009. p. 95-14

TARDIF, Maurice. Saberes profissionais dos professores e conhecimentos universitários. Revista Brasileira de Educação, n. 13, jan-fev-mar-abr 2000. 